\title{
Reducing patient surge: community based social networks as first responders
}

\author{
Alan Kirschenbaum ${ }^{1}$ \\ Received: 17 July 2020 / Accepted: 2 March 2021 / Published online: 23 March 2021 \\ (c) The Author(s), under exclusive licence to Springer Nature B.V. 2021
}

\begin{abstract}
A major challenge for health services worldwide is in providing adequate medical care during mass disasters. The ongoing COVID-19 pandemic highlights this difficulty. Patient surge, a consequence of most types of disasters that contribute to trauma experiences, is a primary factor in disrupting such care as it is composed of worried well persons and those experiencing psychosocial trauma that can severely disrupt and overwhelm effective acute hospital based health care. We review the literature and propose a potential solution framework to reduce such a surge that relies on exploiting community social networks as first responders. We utilize and integrate literature based evidence on patient surge, community disaster behaviors and community based informal social networks to examine reasons for patient surge to hospitals. We then propose that leveraging community based social networks as a potent deterrent for non-critically injured, especially those who have experienced psychosocial trauma or the worried well, from seeking hospital care during ongoing disasters. By emphasizing the social capital inherent in community based social networks, this perspective posits an alternative cost-effective means of reducing patient surge.
\end{abstract}

Keywords Patient surge $\cdot$ Social networks $\cdot$ Disasters $\cdot$ Surge model $\cdot$ Walking worried

\section{Introduction}

During major disasters, the number of injured persons far outnumber those killed (UN 2015; Phalkey et al. 2011; Rotheray et al. 2012). A closer look at the injured suggests that a large number who report to emergency medical facilities for help suffer various forms of psychosocial trauma, especially the 'worried well' who perceive or have symptoms of various diseases (Norris et al. 2010; Reis et al. 2007). This emphasis on psychosocial trauma patients is critical as while there may not be a need for immediate medical care, they have a profound effect on the management of a mass-casualty incident. (Peleg and Kellermann 2009; Bloch et al. 2007). While such psychosocial trauma has been noted across all types of disasters (Reifels et al. 2013), it is particularly critical during cascading environmental disasters that may also lead to a surge of worried well, who show somatic symptoms

Alan Kirschenbaum

avik@g.technion.ac.il

36586 Sde Yakov, Israel 
mimicking exposure symptoms (Bullock et al. 2018; Meredith et al. 2011b). While health teams deal with recovery and identification of the dead and emergency hospital teams try to provide help to the critically injured, there remain a very large pool of persons who also are in need of psychosocial medical help at and around the disaster site. If care is not received at the epicenter of the disaster area, they too will look for help at the closest medical facility creating a situation of potential "patient surge". This situation has been described in a number of disaster studies with some estimates that such patients may comprise as many as 20 times the number of legitimate acute care patients (Stone 2007). In these cases, it might be helpful to distinguish those persons considered 'worried well' who tend to self-diagnose themselves and are considered a psychological rather than medical patient from those individuals affected by psychosocial trauma or acute injuries. While this type of behavior is prevalent in CBRN type disasters where there is a far greater surge of psychosocial trauma patients to hospitals than physically injured (Beaton et al. 2005), hospital surge among the worried well for natural disasters and terror acts can also initially outnumber those with physical injuries (Peltan 2009; Shalev and Freedman 2005).

A series of studies after Hurricane Katrina revealed the extent of such trauma that extended far outside the impact area and the various means of coping (LaJoie et al. 2010). Surveys in New York City, for example, showed that substantial numbers not directly affected by the attack exhibiting similar PTSD symptoms (Galea et al. 2003). Additional research on the aftermath of earthquakes confirm the widespread effect of psychosocial trauma on diverse groups in and outside the disaster area (Livanou et al. 2002; Attfield et al. 2015). Other studies point out that such surges are particularly prevalent in cases of chemical, biological or radiation type disasters especially toxic spills (Svendsen et al. 2012), various environmental hazards and most recently the Corona Virus pandemic (Villa 2020); all the consequence of an initial disaster (Stellman et al. 2008).

Hospitals, as prime facilities in providing acute care solutions in cases of mass casualties, therefore, face the prospect that they will likely be inundated by critically injured but in addition a patient surge composed primarily of what has been described as 'worried well' and persons experiencing psychosocial trauma who display various levels of traumatic behavior that may/or may not be related to minor physical injuries (Meredith et al. 2011a). Such a patient surge can potentially negatively affect levels of health care for the seriously injured by diluting resources and priorities (Evans and Kim 2006). This means that normal day-to-day capacity will be overwhelmed in terms of a hospitals pool of available human resources and material (Stratton and Tyler 2006). Along with this is the estimated financial costs involved whereas an estimated fifty percent saving in hospital care costs would be saved if such patients who are not in need of acute care could be treated outside the hospital facilities (Barton 1999).

Several solutions have been proposed to deal with the expected surge and potential disruption of health care services (Kaji et al. 2006; Eastman et al. 2007). For the most part, they are focused on the medical facilities internal organizational rearrangement and/or structural changes to deal with a surge. For example, preparing hospitals with a sufficient capacity of medical supplies and infrastructure systems (Tosh et al. 2014) and having overflow plans for redistributing patients both internally and to other hospital facilities (Adalja et al. 2014; O'Leary 2004). Another solution are "Mild Casualty Centers" which take in mainly psychosocial trauma patients (Leiba et al. 2006). However, these organizational solutions assume that a patient surge is inevitable and that a simple realigning of the hospital structure to accommodate such a surge will be sufficient to provide the needed medical help to disaster victims (Nates 2004). This is unlikely to be the case if a mass causality disaster occurs when medical facilities - that are not prepared for such a large surge even 
during 'normal' times-will be overwhelmed. One possible solution for such patient surge of non-acute patients, primarily those suffering from psychosocial trauma and/or the worried well, is the possibility of ameliorating it to manageable levels by focusing on reducing the flow at its source.

To this end we will explore an alternative means to diminish such a surge of non-acutecare persons, namely utilizing community social networks and framing the issue of patient surge as a decision making process weighing the benefits or costs of staying in place or evacuating to a medical facility. This will allow us to focus on the source (origin) of the surge and propose a means to restrain it, thereby reducing the pressure on hospital facilities to realign its resources so as to be able to help acute injured patients who depend on immediate professional health care.

\subsection{Staged process}

The literature on patient surge to medical facilities covers numerous natural and humanmade types of mass disasters; from localized events to pandemics. What is clear is that patient surge can be detrimental to both the health of the potential patients and catastrophic to health facilities ability to cope (Aghababian et al. 1994). Generally, "patient surge" has been recognized as a critical issue in the maintenance of a hospitals operational continuity leading medical facilities to prepare for what is termed "Surge Capacity", or the ability to handle massive and immediate overload of emergency services (Hick et al. 2014). This recognition of preparing for "surge capacity" has led to a number of government sponsored studies (GAO Reports 2008). More importantly, the concept of "surge capacity", as depicted in these studies, takes into account the need to view disasters as events that occur over time with the inflow of patients occurring in three distinct stage; an Initial Surge stage consisting of a wave of those injured who tend to be located nearest the medical facility (Einav et al. 2004) followed by a second wave of patient inflow consists of injured persons collected by various official emergency ambulance or rescue teams ((Kuwata and Takada 2004) and the triage system implemented by medical personnel at the disaster scene. (Dean and Nair 2014). A Third wave is composed of a combination of "walking wounded" and "worried well" who may exhibit minor injuries and particularly psychosocial trauma (North and Pfefferbaum 2013).

\subsection{Triage and surge}

As noted, the seriously injured are likely to have been evacuated during or immediately after a disaster by medical personnel in ambulances or taken to hospitals by friends or neighbors employing local private/public transportation (Cassuto and Tarnow 2003). As medical teams at the disaster site follow the traditional triage system, which prioritize those with immediate life threatening injuries, this usually means delaying care of persons with less severe injuries, especially psychosocial trauma (van Rein et al. 2017). Some evidence even suggest that triage for psychologically traumatized disaster victims at the disaster may not be feasible or effective as the type of care needed requires professional psychiatric personnel at the scene and/or a non-hospital setting as well as the need for arranging long term care (North and Pfefferbaum 2013; Engel et al. 2007). By doing so, traditional medical triage inadvertently creates a growing pool of persons with less critical injuries who will likely seek medical care if not treated within a reasonable amount of time. It can 
be assumed that this group of persons waiting for help and exhibiting psychosocial trauma symptoms will —if no help arrives-form the third major surge to hospitals.

\subsection{Local community services}

Given the recognition for the need to treat trauma victims (both from direct and indirect exposure to a disaster), as a means to avoid a patient surge, taking advantage of local community based mental health facilities has been suggested (Lewin et al.. 2005). However, such local community based mental health clinics are far and few between, mainly in nations with advanced medical health systems and concentrated primarily in urban areas (Ricketts 2002). Even when available, such clinics, even during normal times, are over extended (Pandya 2013), making their usefulness problematic in a mass disaster. This lack of local mental health facilities becomes even more critical in an epidemic that can trigger psychosocial distress symptoms when infections are not localized, but spread across boundaries and requiring specialized isolation facilities and quarantining (Di Giuseppe et al. 2020; Stewart-Ibarra et al. 2017). Despite the scattered community based mental health clinics to deal with disaster victims, they do provide a window of opportunity for supportive social networks, which, if robust, can reduce patient surge into hospitals by creating a local community based safety net and incentive for those affected to remain within their communities. This is critical in considering patient surge as it has been repeatedly noted that the psychosocial trauma generated by disasters is far reaching in terms of numbers and geographic location (Bullock et al. 2018). The degree that this incentive will apply may well depend on the strength of the social networks among those in the affected disaster communities (Kirschenbaum 2006) as evidenced by recent literature strongly linking the strength of social networks and psychosocial support to reduce stress and anxiety in a crisis (Iwasaki et al. 2017). This potential ability of local community social networks to offset the attraction of hospitals in providing psychosocial trauma therapy in the disaster, therefore, provides an alternative perspective to patient surge; one that contributes to a positive interactive effect on increased health measures associated with community resilience (Poortinga 2012) and more specifically in ameliorating post disaster trauma (Charuvastra and Cloitre 2008; Sippel et al. 2015; Willis et al. 1997). In some cases specific programs have been advanced to enhance such social support networks as a means of dampening trauma; from school shootings for students (Turunen et al. 2014) to the use of interactive Internet therapies (Feather et al. 2016). To more clearly understand this possibility, patient surge will be viewed as a type of temporary move to seek a critical service made by persons affected by a mass disaster. As such, the decision to seek help at a medical facility for those suffering from trauma is subject to a host of factors that include not only geographic and accessibility factors but the strength of social networks at ones residence.

\subsection{Decision to seek medical help}

During and after a mass disaster, those injured or suffering from psychosocial trauma as well as "the worried well" have the option in seeking help within their own local community or leaving the disaster area in search of medical care. This option, in contrast to the classic hospital surge model based on a single directional move, allows us the opportunity to examine 'surge' from the perspective of not only the hospitals attraction but also from the perspective of a disaster community's attraction to draw or retain persons into remaining in or near their residence. 
Evidence abounds that supports an option to remain close to "home" and suggests that a large number of those with minor injuries, psychosocially traumatized and worried well will seek (para) medical care primarily with the help of nearby family and/or friends and in some cases even strangers. Evidence related to 'helping behavior' during emergencies (Fischer et al. 2011) shows that when care is accessible, or close to where persons are injured and involves those whom they trust (Bloch et al. 2007) or positive bystander behavior (Kirschenbaum and Rapaport 2020), there is the likelihood that it will act to dampen immediate rush to external disaster area medical facilities.

The factors that attract potential psychosocial trauma patients from leaving their community despite the disaster and their clinical medical state suggest the possibility that unlike the traditional medical patient surge model where inhabitants of the disaster area perceive a hospital as the only positive alternative, there may be counter factors holding them in place. We argue that the community of residence, especially its inherent social networks, acts to draw and retain persons to remain, particularly if given long waiting periods due to low priority for medical evacuation and triage designating them as not needing immediate hospital based care.

An important component to this alternative surge model is the focus on a "disaster community". The underlying thrust here is that numerous studies have demonstrated that despite the extensiveness of a disaster, persons involved usually relate to their immediate social and physical environment, and tend to help those within their immediate physical area (Nelson 1973). On this basis, the concept of a disaster community is defined in relation to various levels of the density of social networks in physical proximity (micro-neighborhood to macro-neighborhood (Kirschenbaum 2004). This perspective has strong empirical support in a number of disaster studies (Silver and Grek-Martin 2015) and includes various disaster behaviors linked to social network interactions that, for example, include neighborhood evacuations (Sadri et al. 2017) and community recovery processes (Varda 2017). In the case of patient surge during or after a disaster, a number of positive attracting factors in the disaster community would include the availability of medical care in the form of local community health clinics (if still operable). More significant for the decision process is the degree of density of social support networks composed of family, friends and neighbors in the disaster community; all of whom have been associated with ameliorating disaster generated mental health trauma symptoms and behaviors. This is especially important as the majority of potential patient surge will depend on the type of disaster and its impact on affecting large groups of population with psychological rather than physical injuries.

\subsection{Deflectors of patient surge}

In addition to factors that would positively affect a decision to remain in the disaster area are a series of intervening factors affecting a decision that include the inability of hospitals to help due to potential physical damage to the hospitals themselves or lack of supplies, power failure and the absence of critical human resources (e.g., physicians, nurses, maintenance) (Achour et al. 2011). In addition is the 'time-cost' factor of getting to a hospital facility when transportation infrastructure systems are disrupted, especially as the time factor is decisive in attaining lifesaving medical treatment. On a more positive side are the community based health clinics that act as pivotal points of social life revolving around the medical needs of family, friends and neighbors. These also provide positive weights against surging toward hospitals. For example, local 
school based health centers (Bersamin et al. 2016), community mental health outpatient care ( Myklebust and Wynn 2016), health services for native and immigrant elderly (Verhagen et al. 2013) and already established home care networks by official health employees or volunteers (Mashau et al. 2016) are instrumental in community resilience. By maintaining operational viability after a disaster, they can act as a deterrent to leaving. In addition, such health centers foster community social networks and are characteristic of a resilient community, affecting the level of both physical and mental health of its members (Plough et al. 2013; Wells et al. 2013; Morton and Lurie 2013). In its capacity of promoting 'social network support', such community health centers positively contribute to the psychosocial health of the population (Berkman and Glass 2000; Smith and Christakis 2008). In case of a disaster such community social network support are translated by its members into concrete actions of providing help to each other. Maintaining operational viability is helped by the fact that most such community health centers are mainly staffed by local residents (Witmer et al. 1995). In cases of disasters, including terrorism, these social bonds act to ameliorate stressors and provide prosocial activities that bring a degree of normalcy to an uncertain situation. While these social networks in and of themselves cannot be described as "medical" in the sense of providing acute care for physical injuries, they do provide psychosocial support networks for those who have undergone a trauma and bereavement that are associated with a disaster (Hikichi et al. 2016. This type of psychosocial 'first aid' is important but there still requires more definitive help which can be attained at a later point.

In addition to the impetus that community health centers have on developing social networks, are the daily encounters among community members in local neighborhood schools, shopping centers and community centers. An important characteristic of these community based social networks is that they, unlike official positions within an organizational setting, are formed through informal person to person interactions and maintained through a binding psychological contract of its members. Such types of psychological contracts are developed in multiple settings: within their larger community oriented organizations (Dabos and Rousseau 2004), through non-profit local community agencies based primarily on volunteerism (Stirling et al. 2011) and above all among neighbors and friends in microneighborhoods (Kirschenbaum 2004).

An additional attractive factor at the disaster site are the local residents themselves who in times of emergencies act as first responders in terms of helping their neighbors both physically and psychologically (Lalone 2012). These type of skills are related to the community members' social capital. For example, persons with basic skills in 'psychological first aid' such as teachers can be tapped as well as those local residents with para-medical skills to deal with the first stages of PTSD minor ambulatory injuries (Hoppe et al. 2015). This type of 'helping my neighbor' behavior during emergencies is more effective if even minimum first aid training is provided virtually (Stubbe et al. 2017). Such 'helping' has been shown to be very powerful as it is based on community networks that foster 'neighborliness' and a willingness to help those within their own community social network (Casagrande et al. 2015).

Another set of potential attractive factors in the disaster community is the availability of material resources in terms of both equipment and human resources. For example, local people in construction occupations as well as mechanical equipment may be available for search \& rescue (Chen and Pena-Mora 2011). Local community storeowners or food market chains have food, water and basic first aid supplies available that can be distributed immediately to those in need. For those whose homes are damaged or destroyed, neighborhood community centers, social clubs and especially neighbors and relative's homes have 
proven to be appropriate for temporary shelters (Mesa-Arango et al. 2013). In most cases where evacuation is necessary, neighbors, relatives and friends provide temporary shelter.

Taken together, a local disaster community has embedded within it a number of immediate resources that can offset the attraction of a hospital for those persons having experienced psychosocial trauma. These positive assets might act to counter balance the pull of hospital services and thereby reduce patient surge.

\subsection{Community based social help networks}

To enhance the positive attraction for persons experiencing various forms of psychosocial trauma to remain in their disaster community would likely necessitate having a mechanism in place that would provide immediate accessibility for support: either from existing neighborhood based organizations or informal groups of neighbors and friends. To some extent such formal community agencies exist in the form of 'self-help' programs. In most cases, these community programs have been developed top-down with external agencies providing the guidelines and resources with the aim of building resilient communities (FEMA 2016; Linnerooth-Bayer and Mechler 2007). The recognition of the need for community resilience is not new and has led, in part, to the development of a number of community based "self-help" programs around the globe (Foster 2002). Needless to say, such social support has been found to be critical in cases of disasters and recovery. They have taken different forms and employed different strategies but all are based on utilizing local populations to help themselves and their neighbors when a disaster occurs. In some cases, communities have self-organized help groups based on volunteers and community NGO based organizations (Chen et al. 2006). In other less frequent cases, the self-organization is based on family, clan or ethnic group affiliation (Allen 2006; Norris and Alegria 2005).

The resilient communities approach is understandable in light of the likely lack of external resources available to deal with a mass disaster. As the time-line and availability of resources determines the extent of deaths and injuries to people and damage to property, having the ability to utilize local human and material resources within the disaster area is critical. A careful look at these programs, however, shows that the majority are primarily concerned with search $\&$ rescue or first aid training to help those physically injured. All tend to focus on the training of specific small sub-groups-usually volunteers - tasked with preparing and/or dealing with the immediate consequences of a disaster. However, what is missing are efforts to take advantage of the extensive neighbor-family-friendship networks to provide psychosocial support that might deter patient surge.

\section{Latent networks in aftermath of disasters}

The understanding among medical professionals to treat psychosocial trauma as a public health issue has led to a number of recent community based programs specifically targeting the psychosocial impact of trauma (Bodas et al. 2015; Andrulis et al. 2007) and particularly utilization of community networks as part of the healing process (Walsh 2007). These programs, however, only touch the tip of the iceberg given the numerous latent social network based health and support services within or adjacent to the disaster community. As was noted, communities are layered in terms of supportive social networks from the level of the micro-neighborhood connecting physically close neighbors to connections via community centers, social clubs, health clinics and educational facilities. Many of these 
social networks are activated during disasters from a dormant state to one that is utilized by survivors; emerging as a powerful potential means for those affected both physically and psychosocially to cope and recover. In the past such emergent forms of social organizing were viewed as 'disaster subcultures' and more recently as 'latent communities' (Lowe and Fothergill 2003). Nurturing them are mass telecommunications via the social media. Examples abound as we have seen in the case of floods (Semaan and Mark 2011) and prosocial help groups in such diverse disasters from terror attacks (Kirschenbaum and Rapaport 2009) to hurricanes (Rodríguez et al. 2006).

We argue that the emergence of latent social networks that act to ameliorate psychosocial trauma through social group support encourage 'helping' behavior that can act to reduce patient surge to hospitals by making their neighborhoods and local facilities attractive and a reliable place to obtain support and help. These latent networks, however, do not exist in a vacuum. Recent research in Japan has shown the formation of such social networks to be influenced by people's social capital and culturally expected behaviors during a crisis (Aldrich 2017). To activate such social capital, public authorities have, for example, organized community based sports events, 'block-parties', friendly public spaces (neighborhood parks, play grounds) that increase neighborhood and community members' interactions; a means to develop and enhance such local social networks and build up a reserve of socially based capital among its members. Another source of such latent social networks are embedded in "natural ecological areas" based on demographically homogeneous neighborhoods reflecting social network catalysts such as ethnicity, immigrant and family status, religious orientation as well as socioeconomic status.

\section{Conclusions}

Proposed solutions to avoid hospital facilities from being overwhelmed by patient surge during a mass disaster have generally focused on restructuring and prioritizing hospital resources. Little attention has been focused on filtering the source populations who form the majority of the surge; namely persons exhibiting psychosocial trauma symptoms; worried well individuals not needing immediate acute medical care, but nevertheless perceive themselves as in need of medical help. A solution proposed here, supported by a wealth of research in disaster behavior and community social networks-would be to provide care for such patients within their community of residence; thereby reducing such a surge. Unlike proposals that suggest setting up community trauma clinics that would very likely be compromised during a mass disaster and are usually overloaded even during 'normal' times, our suggested solution goes beyond such local trauma facilities and lies within the context of the social capital inherent in the members of communities themselves.

The key is to invest in enhancing the social capital already embedded in local communities through cost-effective alternative means (e.g., local community based training) that leverages existing social networks composed of neighbors, friends, relatives and people with similar skill sets and more importantly, strong social bonds. These social networks can vary in size and composition but each has the ability for promoting and providing self-help support that can ameliorate psychosocial trauma symptoms among its members as well as with minimum training, provide basic medical first aid help to those with minor injuries. These "in-house" social network support systems can then act to deter hospital seeking and at the same time encourage network members to remain in place and help each other. In a large sense, enhancing such social network capital is a form of developing a psychological 
contract among its members that is far more binding than formal organizational task obligations which can much more easily be breached (Robinson and Morrison 2000).

By focusing on disaster communities as layers of social networks embedded with local residents' social capital, patient surge takes on a new meaning by placing it into a framework that allows for the residents to make decisions concerning their need for medical care and where to obtain it. As a bottom-up perspective, it builds on an already existing platform that needs minimum financial effort to strengthen. The consequences will likely be a drastic reduction in patient surge to hospitals that will allow exiting medical institution to operate effectively during and after mass disasters.

Funding This manuscript was not funded by any institution, public or private.

\section{Declarations}

Conflict of interest There is no conflict of interests in the preparation of the manuscript.

Code availability As the manuscript was based on existing research results, no data/codes are available.

\section{References}

Achour N, Miyajima M, Kitaura M, Price A (2011) Earthquake-induced structural and nonstructural damage in hospitals. Earthquake Spectra 27(3):617-634

Adalja AA, Watson M, Bouri N, Minton K, Morhard RC, Toner ES (2014) Absorbing citywide patient surge during hurricane sandy: a case study in accommodating multiple hospital evacuations. Ann Emerg Med 64(1):66-73

Aghababian R, Lewis CP, Gans L, Curley FJ (1994) Disasters within hospitals. Ann Emerg Med 23(4):771-777

Aldrich DP. Recovering from disasters: Social networks matter more than bottled water and batteries. 2017. www.theconversation.com.

Allen KM (2006) Community-based disaster preparedness and climate adaptation: local capacity-building in the Philippines. Disasters 30(1):81-101

Andrulis DP, Siddiqui NJ, Gantner JL (2007) Preparing racially and ethnically diverse communities for public health emergencies. Health Aff 26(5):1269-1279

Attfield KR, Dobson CB, Henn JB, Acosta M, Smorodinsky S, Wilken JA, Barreau T, Schreiber M, Windham GC, Materna BL, Roisman R (2015) Injuries and traumatic psychological exposures associated with the south napa earthquake - California, 2014. Morb Mortal Wkly Rep 64(35):975-978

Beaton R, Stergachis A, Oberle M, Bridges E, Nemuth M, Thomas T (2005) The Sarin gas attacks on the Tokyo subway- years later/Lessons learned. Traumatology 11(2):103-119

Barton R (1999) Psychosocial rehabilitation services in community support systems: a review of outcomes and policy recommendations. Psychiatr Serv 50(4):525-534

Berkman LF, Glass T (2000) Social integration, social networks, social support, and health. Social Epidemiol 1:137-173

Bersamin MM, Fisher DA, Gaidus AJ, Gruenewald PJ (2016) School-based health centers' presence. the role of school and community factors. Am J Prev Med 51(6):926-932

Bloch TH, Leiba A, Veaacnin N, Paizer Y, Schwartz D, Kraskas A, Weiss G, Goldberg A, Bar-Dayan Y (2007) Managing mild casualties in mass-casualty incidents: lessons learned from an aborted terrorist attack. Prehosp Disaster Med 22(3):181-185

Bodas M, Ben-Gershon B, Rubinstein Z, Bergman-Levy PK (2015) The evolution of the emergency mental health system in Israel - from the 1980's until today. Israel J Health Policy Res 4:25

Bullock W, Reed-Smith E, Heligman C (2018) Managing the "Worried Well" during a large-scale incident. J Emerg Manag 16:1

Casagrande DG, Mcllvaine-Newsad H, Jones EC (2015) Social Networks of help-seeking in different types of disaster responses to the 2008 mississippi river floods. Hum Organ 74(4):351-361 
Cassuto J, Tarnow P (2003) The discotheque fire in Gothenburg 1998 a tragedy among teenagers. Burns 29(5):405-416

Charuvastra A, Cloitre M (2008) Social bonds and posttraumatic stress disorder. Annual Rev Psychol 59:301-328

Chen LC, Liu YC, Chan KC (2006) Integrated community-based disaster management program in Taiwan: a case study of Shang-An village. Nat Haz 37:209

Chen AY, Peña-Mora F, Ouyang Y (2011) A collaborative GIS framework to support equipment distribution for civil engineering disaster response operations. Autom Constr 20(5):637-648. https://doi. org/10.1016/j.autcon.2010.12.007

Dabos GE, Rousseau DM (2004) Social interaction patterns shaping employee psychological contracts. In: Academy ofmanagement proceedings, vol 2004, no. 1. Academy of Management, Briarcliff Manor, NY, pp. N1-N6

Dean MD, Nair SK (2014) Mass-casualty triage: distribution of victims to multiple hospitals using the SAVE model. Eur J Oper Res 238(1):363-373

Engel CC, Locke S, Reissman DB, DeMartino R, Kutz I, McDonald M, Barsky AJ (2007) Terrorism, trauma, and mass casualty triage: How might we solve the latest mind-body problem? Biosecurity Bioterrorism: Biodefense Strategy Pract Sci 5(2):155-163

Di Giuseppe M, Gemignani A, Conversano C (2020) Psychological resources against the traumatic experience of COVID-19 Clinical Neuropsychiatry. J Treat Eval 17(2):85-87

Eastman AL, Rinnert KJ, Nemeth IR, Fowler RL, Minei JP (2007) Alternate site surge capacity in times of public health disaster maintains trauma center and emergency department integrity: hurricane Katrina. J Trauma 63(2):253-257

Einav S, Feigenberg Z, Weissman C, Zaichik D, Caspi G, Kotler D, Freund HR (2004) Evacuation priorities in mass casualty terror-related events: implications for contingency planning. Ann Surg 239(3):304-310

Evans WN, Kim B (2006) Patient outcomes when hospitals experience a surge in admissions. J Health Econ 25(2):365-388

Feather JS, Howson M, Ritchie L, Carter PD, Parry DT, Koziol-McLain J (2016) Evaluation methods for assessing users' psychological experiences of web based psychosocial interventions: a systematic review. J Med Internet Res 18(6):1-13

FEMA Federal Emergency Management Agency, Department of Homeland Security; 2016. https://www. fema.gov/community-emergency-response-teams.

Fischer P, Krueger JI, Greitemeyer T, Vogrincic C, Kastenmüller A, Frey D, Heene M, Wicher M, Kainbacher M (2011) The bystander-effect: a meta-analytic review on bystander intervention in dangerous and non-dangerous emergencies. Psychol Bull 137(4):517-537

Foster G (2002) Supporting community efforts to assist orphans in Africa. New England J Med 346(24): 1907

Galea S, Vlahov D, Resnick H, Ahern J, Susser E, Gold J, Kilpatrick D (2003) Trends of probable posttraumatic stress disorder in New York City after the September 11 terrorist attacks. Am J Epidemiol 158(6):514-524

GAO Reports. Emergency Preparedness: States Are Planning for Medical Surge, but Could Benefit from Shared Guidance for Allocating Scarce Medical Resources 2008. 7/14/2008: 1-59.

Hick JL, Einav S, Hanfling D, Kissoon N, Dichter JR, Devereaux AV, Christian MD, Force Task, for Mass Critical Care, (2014) Surge capacity principles: care of the critically ill and injured during pandemics and disasters: CHEST consensus statement. Chest 146(4):e1S-e16S

Hikichi H, Aida J, Tsuboya T, Kondo K, Kawachi I (2016) Can community social cohesion prevent posttraumatic stress disorder in the aftermath of a disaster? a natural experiment from the 2011 Tohoku earthquake and tsunami. Am J Epidemiol 183(10):902-910

Hoppe A, Heaney CA, Fujishiro K, Gong F, Baron S (2015) Psychosocial work characteristics of personal care and service occupations: a process for developing meaningful measures for a multiethnic workforce. Ethn Health 20(5):474-492

Iwasaki K, Sawada Y, Aldrich DP (2017) Social capital as a shield against anxiety among displaced residents from Fukushima. Nat Hazards 89(1):405-421

Kaji A, Koenig KL, Bey T (2006) Surge capacity for healthcare systems: a conceptual framework. Acad Emerg Med 3(11):1157-1159

Kirschenbaum A (2006) Terror, adaptation and preparedness: a trilogy for survival. J Homel Secur Disaster Manag 3:1547-7355

Kirschenbaum A (2004) Generic sources of disaster communities: a social network approach. International J Sociol Social Policy 24(10/11):94-129 
Kirschenbaum A, Rapaport C (2020) Helping behavior by bystanders: Contrasting individual vs social contextual factors. Int J Disaster Risk Reduction 50:101816

Kirschenbaum A, Rapaport C (2009) Disaster warnings and compliance: the impact of social process factors over time". Int J Mass Emerg Dis 27(3):250-271

Kuwata Y, Takada S (2004) Effective emergency transportation for saving human lives. Nat Hazards 33(1):23-46

LaJoie AS, Sprang G, McKinney WP (2010) Long-term effects of Hurricane Katrina on the psychological well-being of evacuees. Disasters 34(4):1031-1044

LaLone MB (2012) Neighbors helping neighbors: An examination of the social capital mobilization process for community resilience to environmental disasters. J Appl Social Sci 6(2):209-237

Leiba A, Goldberg A, Hourvitz A, Weiss G, Peres M, Karskass A, Schwartz D, Levi Y, Bar-Dayan Y (2006) Who should worry for the 'worried'well', ? Analysis of mild casualties' center drills in nonconventional scenarios.' Prehospital Dis Med 21(6):441-444

Lewin SA, Dick J, Pond P, Zwarenstein M, Aja G, Van Wyk B, Patrick M. Lay health workers in primary and community health care. Cochrane Database Syst Rev, 2005.1. CD004015.

Linnerooth-Bayer J, Mechler R (2007) Disaster safety nets for developing countries: extending publicprivate partnerships. Environ Hazards 7(1):54-61

Livanou M, Bassoglu M, Salcioglu E, Kalendar D (2002) Traumatic stress responses in treatment-seeking earthquake survivors in Turkey. J Nerv Ment Dis 190(12):816-823

Lowe S, Fothergill A. A Need to Help: Emergent Volunteer Behavior after 9/11.Conference Papers, American Sociological Association. 2003 Annual Meeting, Atlanta, GA, p1-25

Mashau NS, Netshandama VO, Mudau M (2016) Self-reported impact of caregiving on voluntary homebased caregivers in Mutale Municipality, South Africa. J African J Primary Health Care Family Med. 8(2):1-5

Meredith LS, Eisenman DP, Tanielian T, Taylor SL et al. (2011a) Prioritizing "psychological" consequences for disaster preparedness and response: a framework for addressing the emotional, behavioral, and cognitive effects of patient surge in large-scale disasters. Dis Med Pub Health Preparedness 5(1):73-80

Meredith LS, Sherbourne CD, Gaillot SJ, Hansell L, Ritschard HV, Parker AM, Wrenn G (2011b) Promoting psychological resilience inthe US military. Rand Health Q 1(2)

Mesa-Arango R, Hasan S, Ukkusuri SV, Murray-Tuite P (2013) Household- level model for hurricane evacuation destination type choice using hurricane ivan data. Nat Hazards Rev 14(1):11-20

Morton MJ, Lurie N (2013) Community resilience and public health practice. Am J Public Health 103(7):1158-1160

Myklebust L, Henrik WR (2016) Inpatients' utilization of GP and psychiatric outpatient care. a comparison of a central institution versus a local institution based system of psychiatry a case register study. Int J Integr Care 16(6):1-3

Nates JL (2004) Combined external and internal hospital disaster: impact and response in a Houston trauma center intensive care unit. Crit Care Med 32(3):686-690

Nelson LD (1973) Proximity to emergency and helping behavior: data from the lubbock tornado disaster. Nonprofit Volunt Sector Q 2(4):194-199

Norris FH, Alegria M (2005) Mental health care for ethnic minority individuals and communities in the aftermath of disasters and mass violence. CNS Spectr 10(2):132-140

Norris FH, Sherrieb K, Galea S (2010) Prevalence and consequences of disaster-related illness and injury from hurricane Ike. special section: disaster management and persons with disabilities. Rehabilitat Psychol 55(3):221-230

North CS, Pfefferbaum B (2013) Mental health response to community disasters: a systematic review. JAMA 310(5):507-518

O'Leary M (2004) The first 72 hours: a community approach to disaster preparedness. IUniverse, New York

Pandya A (2013) A review and retrospective analysis of mental health services provided after the September 11 attacks. Can J Psychiatry 58(3):128-134

Peleg K, Kellermann AL (2009) Enhancing hospital surge capacity for mass casualty events. JAMA 302(5):565-567

Peltan ID (2009) Disaster relief and recovery after a landslide at a small, rural hospital in Guatemala. Prehospital Dis Med 24(6):542

Phalkey R, Reinhardt JD, Marx M (2011) Injury epidemiology after the 2001 Gujarat earthquake in India: a retrospective analysis of injuries treated at a rural hospital in the Kutch district immediately after the disaster. Global Health Action 4:1-9 
Plough A, Fielding JE, Chandra A, Williams M, Eisenman D, Wells KB, Law GY, Fogleman S, Magaña A (2013) Building community disaster resilience: perspectives from a large urban county department of public health. Am J Public Health 103(7):1190-1197

Poortinga W (2012) Community resilience and health: The role of bonding, bridging, and linking aspects of social capital. Health Place 18(2):286-295

Reifels L, Pietrantoni L, Prati G, Kim Y, Kilpatrick DG, Dyb G, O'donnell M (2013) Lessons learned about psychosocial responses to disaster and mass trauma: an international perspective. Eur J Psychotraumatol 4(1):22897

Reis BY, Kohane IS, Mandl KD (2007) An epidemiological network model for disease outbreak detection. PLoS Med 4(6):210

Research. 2017 .20/4: 433-444.

Ricketts TC, Sheps CG (2002) Geography and disparity in health. In: Swift EK (ed) Guidance for the national healthcare disparities report. Institute of Medicine (US) Committee on Guidance for Designing a National Healthcare Disparities Report. National Academies Press (US), Washington, DC

Robinson SL, Morrison EW (2000) The development of psychological contract breach and violation: a longitudinal study. J Organ Behav 21(5):525-546

Rodríguez H, Trainor J, Quarantelli EL (2006) Rising to the challenges of a catastrophe: the emergent and prosocial behavior following Hurricane Katrina. Annals Am Acad Polit Social Sci 604:82-101

Rotheray KR, Aitken P, Goggins WB, Rainer TH, Graham CA (2012) Epidemiology of injuries due to tropical cyclones in Hong Kong: a retrospective observational study. Injury 43(12):2055-2059

Sadri AM, Ukkusuri SV, Gladwin H (2017) The role of social networks and information sources on hurricane evacuation decision making. Nat Hazards Rev 18(3):04017005

Semaan B, Mark G (2011) Technology-mediated social arrangements to resolve breakdowns in infrastructure during ongoing disruption. ACM Trans Computer-Human Interact 18(4):1-21

Shalev AY, Freedman S (2005) PTSD following terrorist attacks: a prospective evaluation. Am J Psychiatry 162(6):1188-1191

Silver A, Grek-Martin J (2015) Now we understand what community really means: reconceptualizing the role of sense of place in the disaster recovery process. J Environ Psychol 42:32-41

Sippel LM, Pietrzak RH, Charney DS, Mayes LC, Southwick SM (2015) How does social support enhance resilience in the trauma-exposed individual? Ecol Soc 20(4):136-145

Smith KP, Christakis NA (2008) Social networks and health. Ann Rev Sociol 34:405-429

Stellman JM, Smith RP, Katz CL, Sharma V, Charney DS, Herbert R, Moline J, Luft BJ, Markowitz S, Udasin I, Harrison D, Baron S, Landrigan PJ, Levin SM, Southwick S (2008) Enduring mental health morbidity and social function impairment in world trade center rescue, recovery, and cleanup workers: the psychological dimension of an environmental health disaster. Environ Health Perspect 116(9):1248-1253

Stewart-Ibarra Anna M, Hargrave Anita, Diaz Avriel, Kenneson Aileen et al. (2017) Psychological distress and zika, dengue and chikungunya symptoms following the 2016 earthquake in bahia de caraquez, ecuador. Int J Environ Res Public Health 14:12

Stirling C, Kilpatrick S, Orpin P (2011) A psychological contract perspective to the link between non-profit organizations' management practices and volunteer sustainability. Hum Resour Dev Int 14(3):321-336

Stone F P. The" worried well" response to CBRN events: Analysis and solutions. 2007. Air University, Maxwell Air Force Base; Counter Proliferation Center. US Government

Stratton SJ, Tyler RD (2006) Characteristics of medical surge capacity demand for sudden-impact disasters. Acad Emerg Med 13(11):1193-1197

Stubbé HE, Van Emmerik ML, Kerstholt JH (2017) Helping behavior in a virtual crisis situation: effects of safety awareness and crisis communication. J Risk Res 20(4):433-444

Svendsen E, Holbrook JR, Chanda D, Bao H, Svendsen ER, Ginsberg JP (2012) Posttraumatic stress and tendency to panic in the aftermath of the chlorine gas disaster in Graniteville, South Carolina. Soc Psychiatry Psychiatr Epidemiol 47(9):1441-1448

Tosh PK, Feldman H, Christian MD, Devereaux AV, Kissoon N, Dichter JR Business and continuity of operations: care of the critically ill and injured during pandemics and disasters: CHEST consensus statement. Task Force for Mass Critical Care; Task Force for Mass Critical Care, Chest [Chest] 2004. ISSN: 1931-3543, 2014 Oct; Vol. 146 (4 Suppl), pp. e103S-17S; Publisher: American 32.

Tosh G, Clifton AV, Xia J, White MM (2014) Physical health care monitoring for people with serious mental illness. Cochrane Database Syst Rev. https://doi.org/10.1002/14651858.CD008298.pub2

Turunen T, Haravuori H, Pihlajamäki JJ, Marttunen M, Punamäki RL (2014) Framework of the outreach after a school shooting and the student's perceptions of the provided support. Eur J Psychotraumatol 5(2): 23079

United Nations, (2015) www.un.org/apps/news/story.asp?NewsID=52627. Accessed Feb 2020 
Varda DM (2017) Strategies for researching social networks in disaster response, recovery, and mitigation. In: Social network analysis of disaster response, recovery, and adaptation. Butterworth-Heinemann, pp 41-56

Verhagen I, Ros WJG, Steunenberg B, de Wit NJ (2013) Culturally sensitive care for elderly immigrants through ethnic community health workers: design and development of a community based intervention programme in the Netherlands. BMC Public Health 13(1):1-8

Walsh F (2007) Traumatic loss and major disasters: Strengthening family and community resilience. Fam Process 46(2):207-227

Wells KB, Springgate BF, Lizaola E, Jones F, Plough A (2013) Community engagement in disaster preparedness and recovery: a tale of two cities-Los Angeles and New Orleans. Psychiatr Clin North Am 36(3):451-466

van Rein EAJ, Gunning AC, Leenen LPH, van Heijl M, Houwert RM, Lichtveld RA (2017) Accuracy of prehospital triage protocols in selecting severely injured patients: a systematic review. J Trauma Acute Care Surg 83(2):328-339

Villa L (2020) Hospitals brace for a patient surge. TIME Magazine 195(11):29-31

Willis K, Cameron P, Igoe P (1997) Building community networks: a road trauma education and training program for rural areas. Aust J Rural Health 5(1):6-10

Witmer A, Seifer SD, Finocchio L, Leslie J, O’Neil EH (1995) Pew health professions commission, Center for the health professions, University of California at San Francisco 94109, USA“Community health workers: integral members of the health care work force. Am J Pub Health 85(8):1055-1058

Publisher's Note Springer Nature remains neutral with regard to jurisdictional claims in published maps and institutional affiliations. 